\title{
Assessing economic, social and environmental impacts on housing prices in Hong Kong: a time-series study of 2006, 2011 and 2016
}

\author{
Jing $\mathrm{Li}^{1} \cdot$ Weixuan Fang ${ }^{2} \cdot$ Yuan $\mathrm{Shi}^{3}$ (D) Chao Ren ${ }^{4}$
}

Received: 1 February 2020 / Accepted: 3 September 2021 / Published online: 16 September 2021 (CThe Author(s), under exclusive licence to Springer Nature B.V. 2021, corrected publication 2021

\begin{abstract}
Given Hong Kong's unique high-density urban environment and limited land resources, more and more general public has been concerned about the living quality. Based on three waves of census data (2006, 2011 and 2016), combined with our spatial-temporal urban environmental database consisting of three local datasets of urban climate and air quality, this paper assesses the impacts of social, economic and environmental factors on the logarithm of housing prices in Hong Kong through linear regression analysis. Specifically, both supply- and demand-side economic factors have significant impacts on housing prices. Demographic factors are not as significant as expected in affecting housing prices. Transportation factors have more significant effects in the short run than in the long run. Environmental factors, including the number of hot night hours, Annual Air Quality Index (AAQI) of nitrogen dioxide $\left(\mathrm{NO}_{2}\right)$ and particulates with particle sizes less than 10 microns $\left(\mathrm{PM}_{10}\right)$, significantly affect housing prices over time. The results have important implications: current policy instruments to prevent housing price escalation are focused on increasing property tax or land supply (economic factors), while little attention is paid to social or environmental factors, which are geographically heterogeneous. Our findings suggest that housing provision in the New Territories may be a feasible solution to alleviate the housing crisis as its demographic pattern, transportation connectivity and air quality are significantly different from Hong Kong Island or Kowloon Peninsula. In regard to urban environmental problems brought by the high-density development in Hong Kong despite land-use saving, intensified urban infrastructure and promotion of public transportation, our study contributes to the understanding of its housing price dynamics from a more holistic perspective by comparing the impacts of economic, social and environmental factors.
\end{abstract}

Keywords Housing prices $\cdot$ Economic factors $\cdot$ Social factors $\cdot$ Environmental factors

Yuan Shi

shiyuan@cuhk.edu.hk

Extended author information available on the last page of the article 


\section{Introduction}

Nowadays, people are increasingly concerned with the nexus between community, environment and healthy living. In the context of Hong Kong, a densely populated metropolis, the health impact of housing and community problems are experienced differently by people in income groups and health dimensions (Wang et al., 2018). For instance, Zhang and Huang (2018) found that the problem of abundant and unhealthy food is more severe than the problem of limited access to healthy food in Hong Kong in proximity to people's homes. A global survey of urban professionals conducted by the Economist Intelligence Unit (2011) further revealed that urban livability and economic growth are inextricably intertwined. As for Hong Kong, a high-income economy by international standard, the situation can be even more complicated as its skyrocketing housing price limits the housing tenure choice of its low- and many middle-income households (Forrest \& Xian, 2018). High housing price as a major challenge to people's living standard is determined by various social, economic and environmental factors.

While previous studies have investigated the economic determinants of housing price, little is known about the combined effects of economic, social and environmental factors on housing price. The main challenge to this research gap is data incompatibility: there are typically two types of variables for explaining housing price, namely economic factors and hedonic factors. The former is at a large scale, such as across cities or regions, while the latter is at a building level, such as unit- or complex- specific. The former sample usually has good control for economic and social factors but is insufficient in controlling environmental factors, while the latter sample cannot control economic factors. To allow the impact study of different factors on housing price, a more comprehensive database is required.

Based on three waves of census data, combined with a spatiotemporal database, it is generated by integrating two datasets on the spatial estimation of air temperature and the counts of hot day/hot night hours developed in our previous urban climate studies and one dataset of Annual Air Quality Index from local environmental protection authority. Details of the three datasets are shown in Table 2. As a part of a series of theme-based research on Hong Kong heat-health risk assessments, the database has been being used for local heat-health and environmental research. This paper makes an extensive comparison of the combined impacts of social, economic and environmental factors on housing prices in Hong Kong at a macro-level. We aim to evaluate to what extent the determinants of housing prices have changed during the period 2006 to 2016 when the average housing price in Hong Kong has increased by 3.6 times (Rating \& Valuation Department, 2019). The remainder of this paper proceeds as follows: Section 2 reviews the literature on various related issues, i.e., high-density living; vertical city; Asian urbanism; housing price determinants (transport, amenity, demography, location, income) and hedonic price modeling. Section 3 describes the data structure and methods used for regression analysis. Section 4 presents the estimation results and discusses their research implications. Section 5 concludes the findings.

\section{Literature review}

Hedonic price modeling is typically used to study the impacts of housing characteristics on real estate prices (i.e., Bao \& Wan, 2004; Chau et al., 2001). In the context of Hong Kong, people are willing to pay for desirable housing attributes such as an apartment at higher floor and shorter distance from CBD (Mok et al., 1995). Choy et al. (2007) found 
that attributes including the property of larger size, higher floor level, better view and proximity to a railway station all require a premium. Basically, there is a consensus that convenient transportation (Cervero \& Murakami, 2009; So et al., 1997; Yiu \& Tam, 2007; Yiu \& Wong, 2005) and scenic view (Hui et al., 2012; Jim \& Chen, 2009; Tse, 2002) tend to increase housing prices. However, buyers' tastes and preferences for other housing attributes may vary substantially (Chan et al., 2008; Mak et al., 2010; Tang \& Yiu, 2010; Wong et al., 2011).

Data availability is a major constraint to input variables into the hedonic modeling (Chau \& Chin, 2003). Tse and Love (2000) classified hedonic price attributes into four categories: structural, physical, neighborhood and environmental. Chau et al. (2004) found that green features such as balcony has a positive effect on housing prices, whereas air and noise pollution have a negative effect on housing prices. Wong (2008) revealed that the outbreak of Severe Acute Respiratory Syndrome (SARS) in 2003 lowered property price by 1.6 percent on average. Zhang et al. (2012) identified that the green roof is not an option for buildings in Hong Kong. Wadu and Wan (2013) discovered that people are willing to pay more for green features recognized by HK-BEAM and $\mathrm{HK}-\mathrm{GBC}$. Interestingly, $\mathrm{Li}$ and $\mathrm{Li}$ (2018) found that the smell from landfill does not have a negative impact on housing prices in Southeast New Territories of Hong Kong. Beyond Hong Kong, there are a few studies focusing on the relationship between environmental factors and housing prices. For instance, Zheng et al. (2010) recognized that home prices are lower in cities with higher ambient pollution.

As a world-class financial center, Hong Kong has scarce land resources for development. High land prices have prompted Hong Kong to adopt a high-density urban development strategy, making it one of the most densely populated cities in the world (Yeh, 2011). There have been debates on the pros and cons of high-density urban development (Clark \& Moir, 2015), as it inevitably brings urban environmental problems despite land use saving land use, intensified urban infrastructure, and promotion of public transportation. In Hong Kong, high-density urban forms reduce urban air ventilation ( $\mathrm{Ng}, 2009)$, and the environmental challenges it brings include, but not limited to, urban heat island effects (Shi et al., 2018a, 2018b), prolonged extreme hot weather (Cai et al., 2017; Shi et al., 2019), and deteriorated outdoor air quality and microclimate condition (Shi et al., 2016). Building morphological forms have been found to be influential to housing price in Hong Kong ( $\mathrm{Li}$ et al., 2018). It has been found that concerns about climatic risks also affect the urban real estate market (Bunten \& Kahn, 2014). Besides that, studies also show that air quality has direct or indirect impacts on housing prices (Kenneth and Michael 2005). For example, in Seoul, another Asian high-density metropolitan area, the benefits of air quality improvement on housing price have been measured by using a spatial hedonic approach (Won Kim et al., 2003). Having said that, there is still a lack of holistic understanding on the impacts of environment-related factors on housing price in Hong Kong. Above-mentioned literature reveals a major research gap about Hong Kong housing price: despite the substantial work that has been done at the micro-level (unitor complex-specific), little is known about the relationship between housing price and macro-level (social, economic and environmental) variables. Although there are a handful of studies about the nexus among social, economic and environmental factors on buildings in Hong Kong (i.e., Chiang et al., 2014, 2016), the spatial-temporal effect of environmental factors on housing price remains underexplored. In particular, the impact of air quality on housing price dynamics requires further exploration. 


\section{Materials and methods}

The yearly data in territorial planning unit (TPU) level were collected for 2006, 2011 and 2016 to evaluate the impact of major socioeconomic and environmental factors on housing price in Hong Kong. In specific, we studied 13 socioeconomic factors and 6 environmental factors for their relationships with housing price growth in Hong Kong.

The socioeconomic factors, including (1) distance from Mass Transit Railway (MTR), (2) population, (3) median age, (4) labor force, (5) labor force participation, (6) median monthly income, (7) the number of households, (8) median household income, (9) median household rent, (10) private permanent housing, (11) degree course attender, (12) place of study in the same district and (13) place of work in the same district, were collected from the official website of Census and Statistic Department of the Government of Hong Kong SAR, while the distance between each representative residence in each TPU and the nearest MTR was calculated by the linear distance in ArcGIS.

Environmental determinants include (1) annual averaged daytime air temperature (temp_d06); (2) annual averaged nighttime air temperature (temp_n15); (3) number of very hot day hours (VHD06); (4) number of hot night hours (HN15); (5) Annual Air Quality Index (AAQI) of nitrogen dioxide $\left(\mathrm{NO}_{2}\right)$ and (6) particulates with particle sizes less than 10 microns, which are known as respirable suspended particulates (RSPs) or PM $_{10}$.

The collected dataset for this study consists of 227 samples in total with 82 in 2006, 79 in 2011 and 66 in 2016. Since the housing price data were not normally distributed, we processed the data into the log form based on 10. All the determinants listed in Tables 1 and 2 are standardized as follows:

$$
X_{\mathrm{std}}=\frac{X-X_{\min }}{X_{\max }-X_{\min }} .
$$

We assumed that the effects of the determinants on housing price were linearly additive. That is the housing price can be described by

$$
\text { Housing price }=\sum_{i=1}^{13} \alpha_{i} x_{i}+\sum_{j=1}^{6} \beta_{j} e_{j},
$$

where $\alpha_{i}$ is the coefficient of the socioeconomic factor $x_{i}$, and $\beta_{j}$ is the coefficient of the environmental factor $e_{j}$. Based on the processed data, we conceived 6 models covering different types of factor to examine the independent effects of socioeconomic variables and environmental determinants, respectively, as well as their interactive effects on housing price in an integrated fashion. To be specific, the first model focuses on environmental factors over three years:

$$
\text { Housing price }=\sum_{j=1}^{6} \beta_{j} e_{j}
$$

The second model focuses on socioeconomic factors over three years:

$$
\text { Housing price }=\sum_{i=1}^{13} \alpha_{i} x_{i} .
$$


Table 1 List of socioeconomic factors with their definitions and data sources

\begin{tabular}{|c|c|}
\hline Factors & Definition and data source \\
\hline Distance from MTR & $\begin{array}{l}\text { The linear distance between the objective residence and its } \\
\text { nearest MTR via the calculation in ArcGIS }\end{array}$ \\
\hline Population & The total number of residents in each TPU (from census data) \\
\hline Median age & The median age of residents in each TPU (from census data) \\
\hline Labor force (person) & $\begin{array}{l}\text { The number of residents who have the ability to work includ- } \\
\text { ing both employed and unemployed people in each TPU } \\
\text { (from census data) }\end{array}$ \\
\hline Labor force participation (\%) & $\begin{array}{l}\text { The percentage of labor force in each TPU via the formula: } \\
\text { f/d*100 }\end{array}$ \\
\hline Median monthly income (HK\$) & $\begin{array}{l}\text { The median monthly income of residents in each TPU (from } \\
\text { census data) }\end{array}$ \\
\hline The number of households & The number of households in each TPU (from census data) \\
\hline Median household income (HK\$) & $\begin{array}{l}\text { The median monthly income of households in each TPU (from } \\
\text { census data) }\end{array}$ \\
\hline Median household rent $(\mathrm{HK} \$)$ & The median rent of households in each TPU (from census data) \\
\hline Private permanent housing (person) & $\begin{array}{l}\text { The number of residents who own their own private permeant } \\
\text { housing in each TPU (from census data) }\end{array}$ \\
\hline Degree course attender (person) & $\begin{array}{l}\text { The number of residents who have ever attended the degree } \\
\text { course in each TPU (from census data) }\end{array}$ \\
\hline Place of study in the same district (person) & $\begin{array}{l}\text { The number of students who live and study in the same TPU } \\
\text { (from census data) }\end{array}$ \\
\hline Place of work in the same district (person) & $\begin{array}{l}\text { The number of employees who live and work in the same TPU } \\
\text { excludes who work at home (from census data) }\end{array}$ \\
\hline
\end{tabular}

The next three models focus on an integration of socioeconomic and environmental factors for the year of 2006, 2011 and 2016, respectively.

$$
\begin{aligned}
& \text { Housing price }{ }^{\text {year }}=\sum_{i=1}^{13} \alpha_{i}^{\text {year }} x_{i}^{\text {year }}+\sum_{j=1}^{6} \beta_{j}^{\text {year }} e_{j}^{\text {year }}, \\
& \text { year }=2006,2011,2016 .
\end{aligned}
$$

The final model integrates all socioeconomic and environmental factors over three years:

$$
\text { Housing price }=\sum_{i=1}^{13} \alpha_{i} x_{i}+\sum_{j=1}^{6} \beta_{j} e_{j},
$$

In order to avoid the collinearity between determinants with similar attributes, each of the six models was further examined by several sub-models with different combinations of considered variables. The number of combinations depends on the number of variables which indicate the same influencing factor of housing price. For six environmental variables, temp_d and temp_n both indicate temperature. As a result, two preliminary sub-models and two optimized sub-models based on these two can be built. For 13 socioeconomic variables, there are four indicators of the number of residents: (1) population; (2) labor force, (3) labor force participation and (6) the number of 


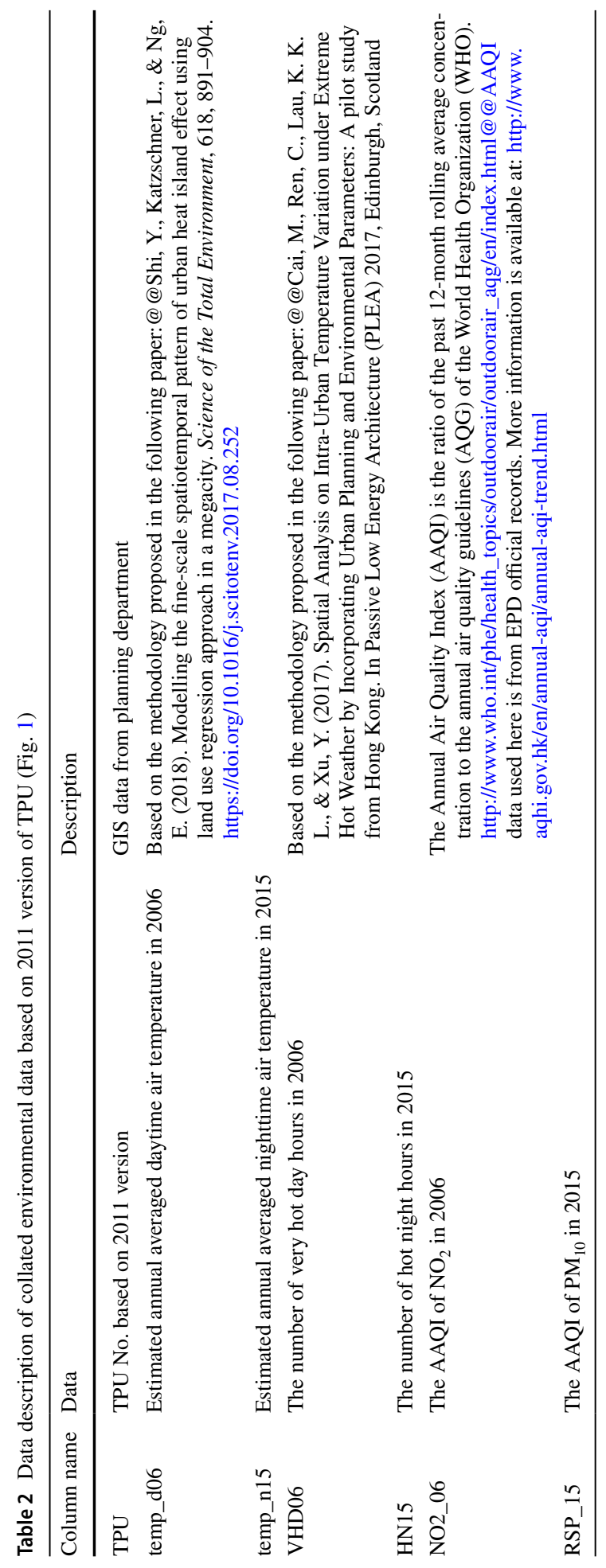


households; and two indicators of the income of residents: (1) median monthly income and (2) median household income. In each sub-model, we selected only one indicator from the number of residents and one from the income of resident to conduct the analysis. Besides, the median household income is specially used to match the number of households. Consequently, there are four initial sub-models in models 2-6. Then, four optimized sub-models can be built, respectively, according to the significance analysis of those four initial sub-models. The full list of variables combination can be found in Tables 3, 4, 5, 6, 7, 8 for the models 1-6, respectively. Then, all the sub-models were calibrated by the corresponding dataset through linear regression analysis.

\section{Result and discussion}

\subsection{Impact of environmental factors}

Table 3 provides the environmental determinants of housing prices, with the residual distribution for models 1 and 2 displayed in Fig. 2. Model 2 is the optimal model from the baseline model 1, while model 4 is the optimal model from the baseline model 3 . In both baseline models, the number of hot night hours also has a significant effect on housing price. As the signs of their impacts are opposite, the variable of $\mathrm{HN}$ is excluded in the optimal models. In models 1 and 2, daytime air temperature has a significant but negative effect on housing price. The impacts of very hot days and AAQIs of $\mathrm{PM}_{10}$ on housing price are significant and negative, while the impact of AAQIs of $\mathrm{NO}_{2}$ on housing price is significant and positive.

Table 3 Environmental determinants of housing price (06\&11\&16)

\begin{tabular}{|c|c|c|c|c|c|}
\hline & & Sub-model 1 & $\begin{array}{l}\text { Sub-model } 2 \text { (opti- } \\
\text { mized model based } \\
\text { on sub-model } 1 \text { ) }\end{array}$ & Sub-model 3 & $\begin{array}{l}\text { Sub-model } 4 \text { (opti- } \\
\text { mized model based } \\
\text { on model } 3 \text { ) }\end{array}$ \\
\hline \multirow[t]{7}{*}{ Parameters } & Constant & 3.905 & 3.907 & 3.961 & 3.962 \\
\hline & Temp_d & $-0.450 *++$ & $-0.390+$ & & \\
\hline & Temp_n & $0.661 * *++$ & $0.592 * *+$ & $0.229 * * *$ & $0.231 * * *$ \\
\hline & $\mathrm{HN}$ & -0.053 & & 0.007 & \\
\hline & VHD & -0.067 & -0.094 & $-0.180 * * *$ & $-0.178 * * *$ \\
\hline & $\mathrm{NO} 2$ & $0.363^{* * *}$ & $0.353 * * *$ & $0.375 * * *$ & $0.377 * * *$ \\
\hline & RSP & $-0.757 * * *$ & $-0.752 * * *$ & $-0.836 * * *$ & $-0.838 * * *$ \\
\hline \multirow[t]{3}{*}{ Reliability } & R Square & 0.594 & 0.594 & 0.589 & 0.589 \\
\hline & Adjusted R Square & 0.583 & 0.584 & 0.580 & 0.582 \\
\hline & Durbin-Watson & 1.069 & 1.056 & 1.008 & 1.009 \\
\hline
\end{tabular}

*Indicates significant at $10 \%$ level, $* *$ indicates significant at $5 \%$ level, $* * *$ indicates significant at $1 \%$ level. + indicates VIF $>10,++$ indicates $\mathrm{VIF}>20,+++$ indicates $\mathrm{VIF}>30$ 


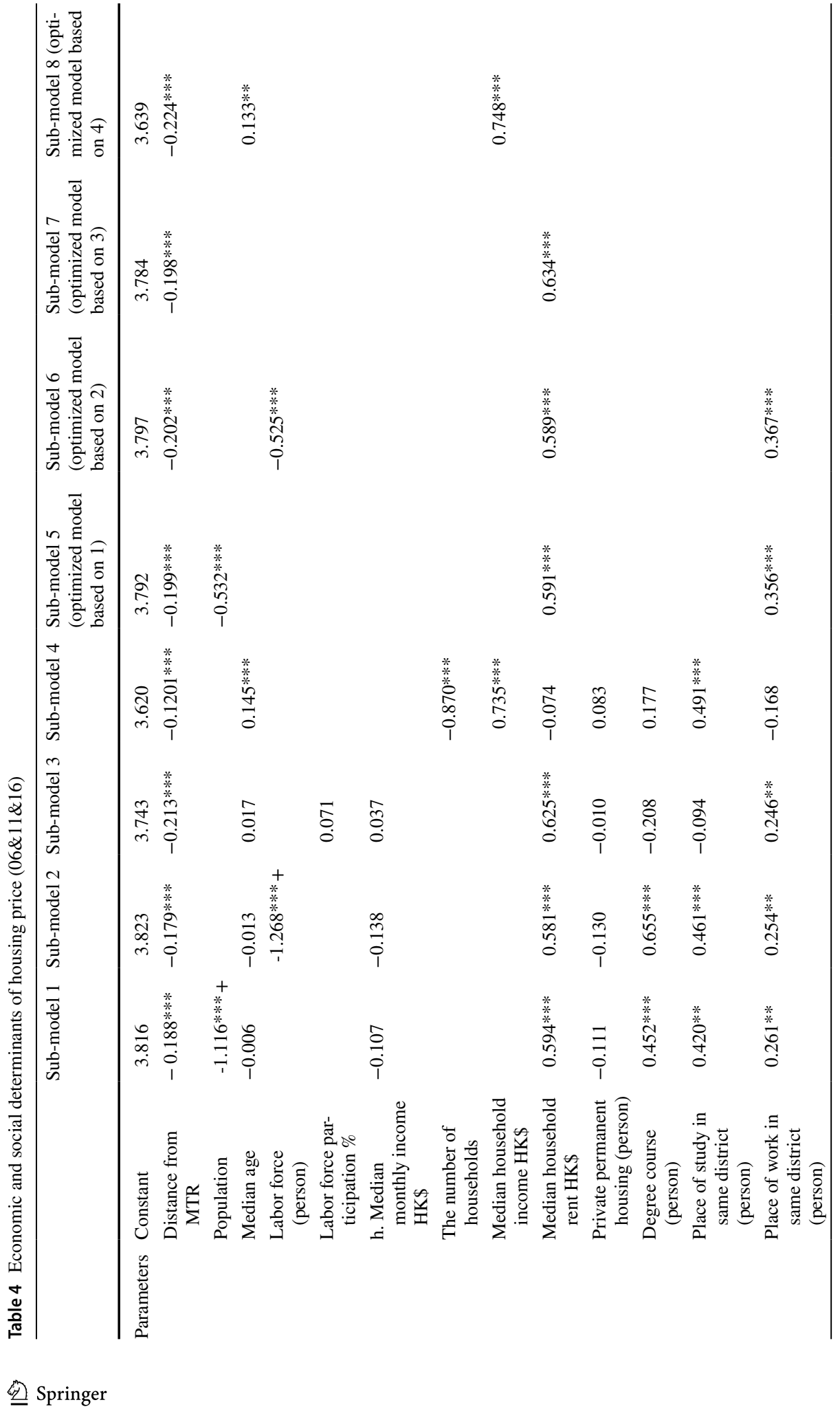




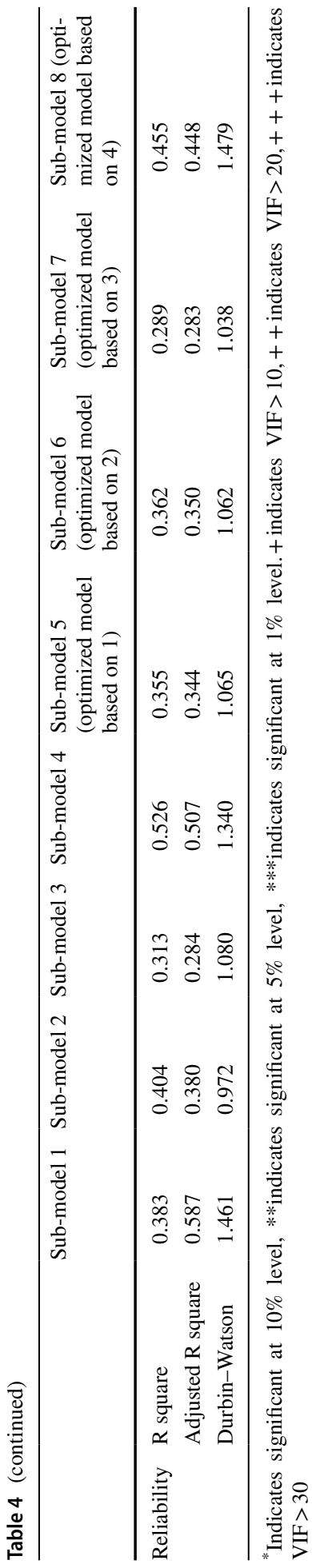




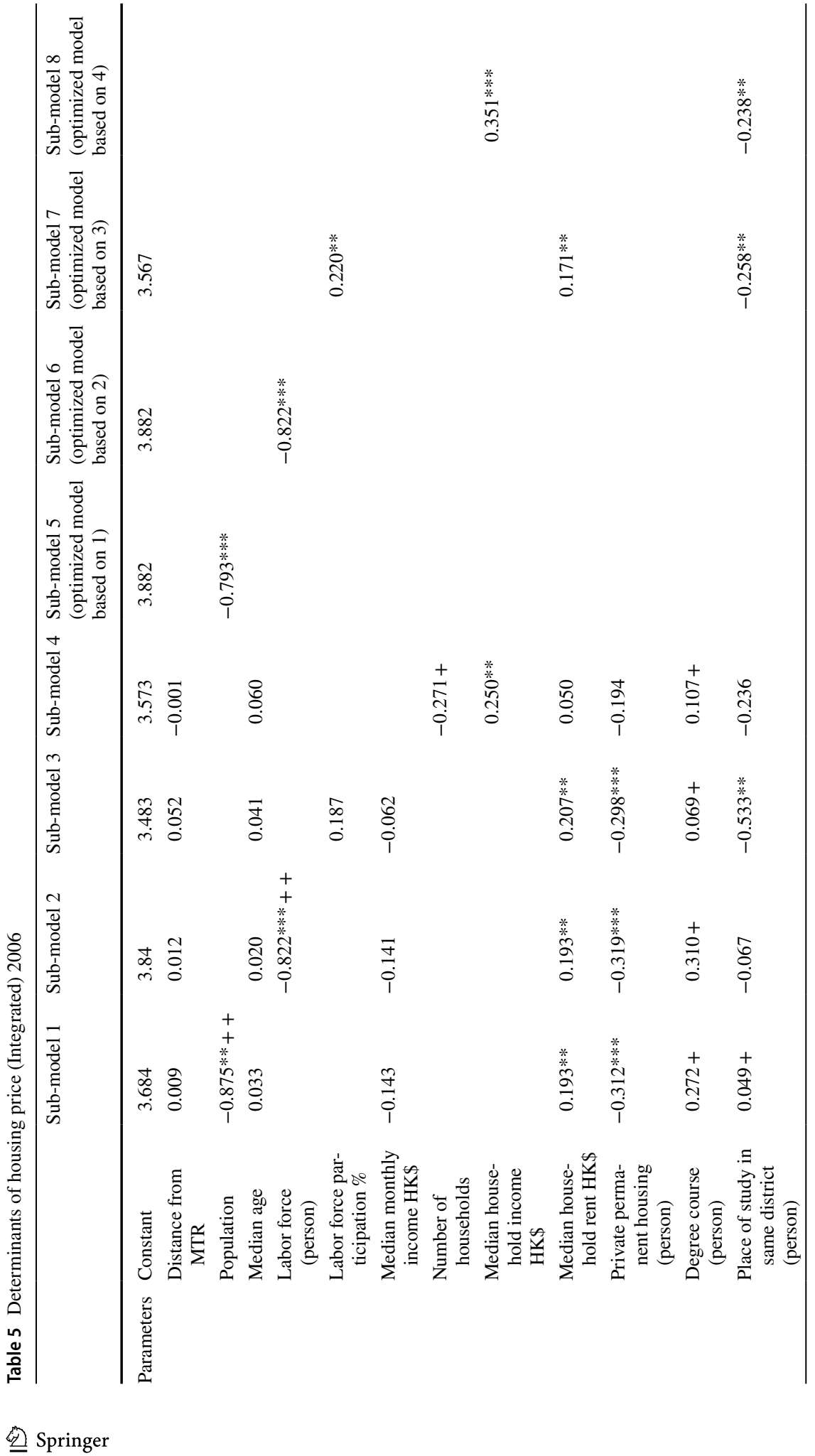




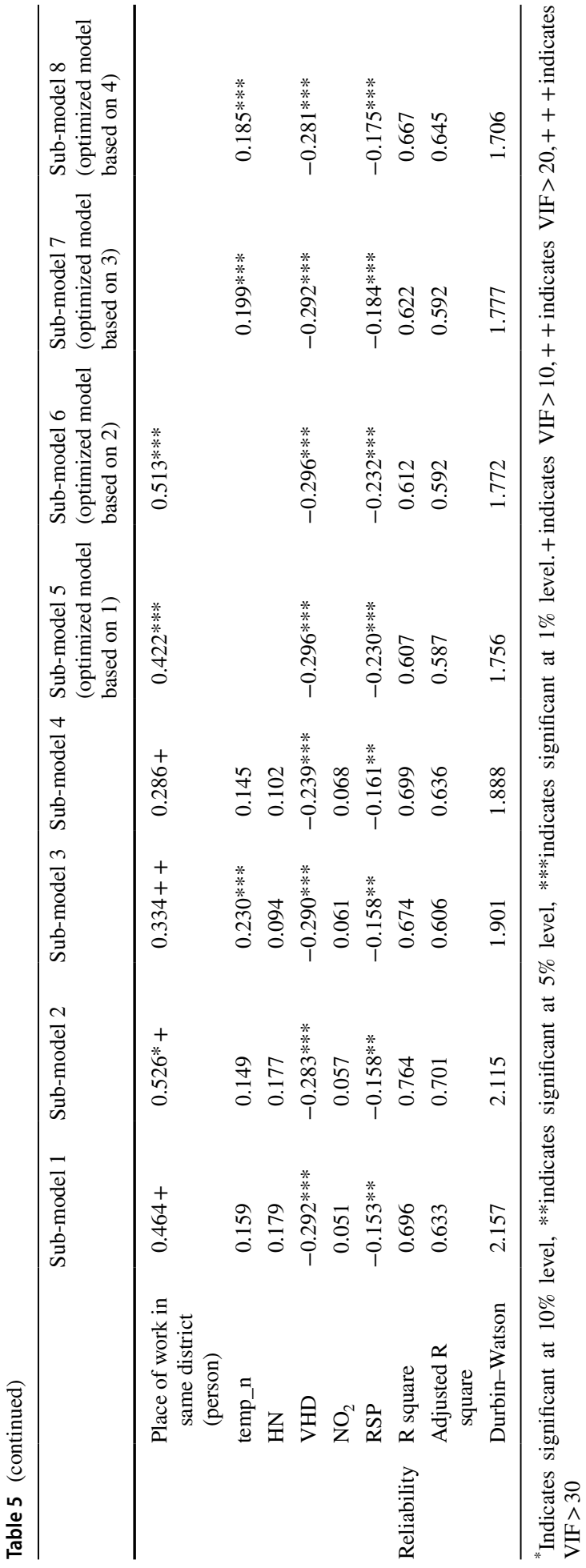




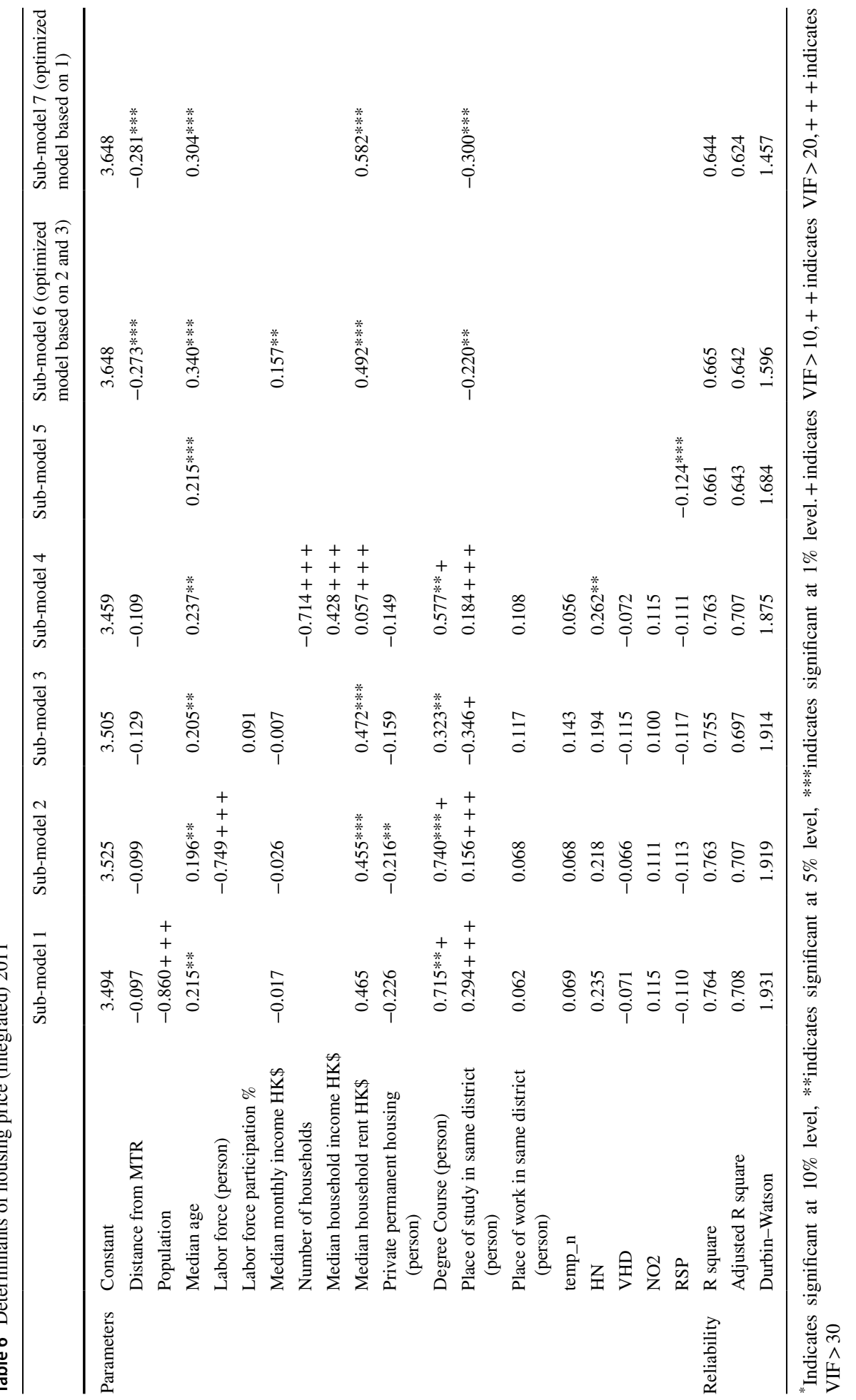




\subsection{Impact of economic and social factors}

Table 4 provides the economic and social factors influencing housing prices, with the associated residual distribution for models 1 and 5 displayed in Fig. 3. Models 5 to 8 are the optimal models from baseline models 1 to 4 . Various factors are consistent in most models regarding their effects on housing price. For instance, the distance to the nearest MTR station has a significant and negative impact on housing price in all models, echoing many studies about the synergy between real estate development and MTR, i.e., the so-called R(railway) + P(property) model (Cervero \& Murakami, 2009; He et al., 2018; So et al., 1997; Tang, 2017; Yiu \& Wong, 2005). Another influential factor is the housing demand, which is reflected in terms of medium household income (models 4 and 8) or medium household rent (models 1-3 and 5-7). It is significantly and positively associated with housing price, which is logically understandable and consistent with the literature (Leung, 2004; Li, 2013, 2016). Education level has a positive impact in models 1 and 2, consistent with the previous work that high education attainment boosts housing price (Choy \& Li, 2017; Wen et al., 2019). However, it is interesting that various demographic variables, i.e., population, labor force and the number of households, have a significant and negative effect on housing price in various models, although they should be demand-side factors that contribute to the housing price increase. One plausible explanation is that they may not be "real" demand, as high housing price has prevented many households from getting on the housing ladder in Hong Kong (Forrest \& Xian, 2018; Li, 2018).

\subsection{Combined impacts over time}

Tables 5, 6, 7 combine the estimation results of economic, social and environmental determinants of housing prices in year 2006, 2011 and 2016, respectively, with their associated residuals in Figs. 4, 5, 6. When cross-sectional data without time effect are used for regression analysis, the impact of MTR distance becomes insignificant although still negative except for models 6 and 7 in year 2011 (see Table 6).

The impacts of other economic, social and environmental factors vary over time. Specifically, medium age has a significant and positive effect on housing price in models 4 and 8 of Table 4, indicating that the purchasing power increases when people become more experienced and better paid. As for year 2006, the impact of medium age is insignificant (Table 5). However, its impact is significant and positive in all models of Table 6 for year 2011, but becomes insignificant again for year 2016 (Table 7). The coefficient of medium age effect for 2011 (ranged from 0.196 to 0.34 ) is higher than the coefficient of average medium age effect from 2006 to 2016 (ranged from 0.133 to 0.145). It is noteworthy that during 2004 and 2015, the Hong Kong government implemented the Capital Investment Entrant Scheme (CIES) which attracted substantial capital inflows of non-local buyers into the local housing market. CIES may hence mediate the effect of local buyers on housing price dynamics in Hong Kong ( $\mathrm{Li}$ et al., 2019), thus making the impact of medium age population insignificant from time to time (Fig. 7).

As for other housing demand indicators, total population (models 1 and 5) and labor force participation (models 2 and 6) still have significant but negative effect on housing price in year 2006, but insignificant in years 2011 and 2016. Medium household income or rent still has a significant and positive effect on housing price in year 2006. 


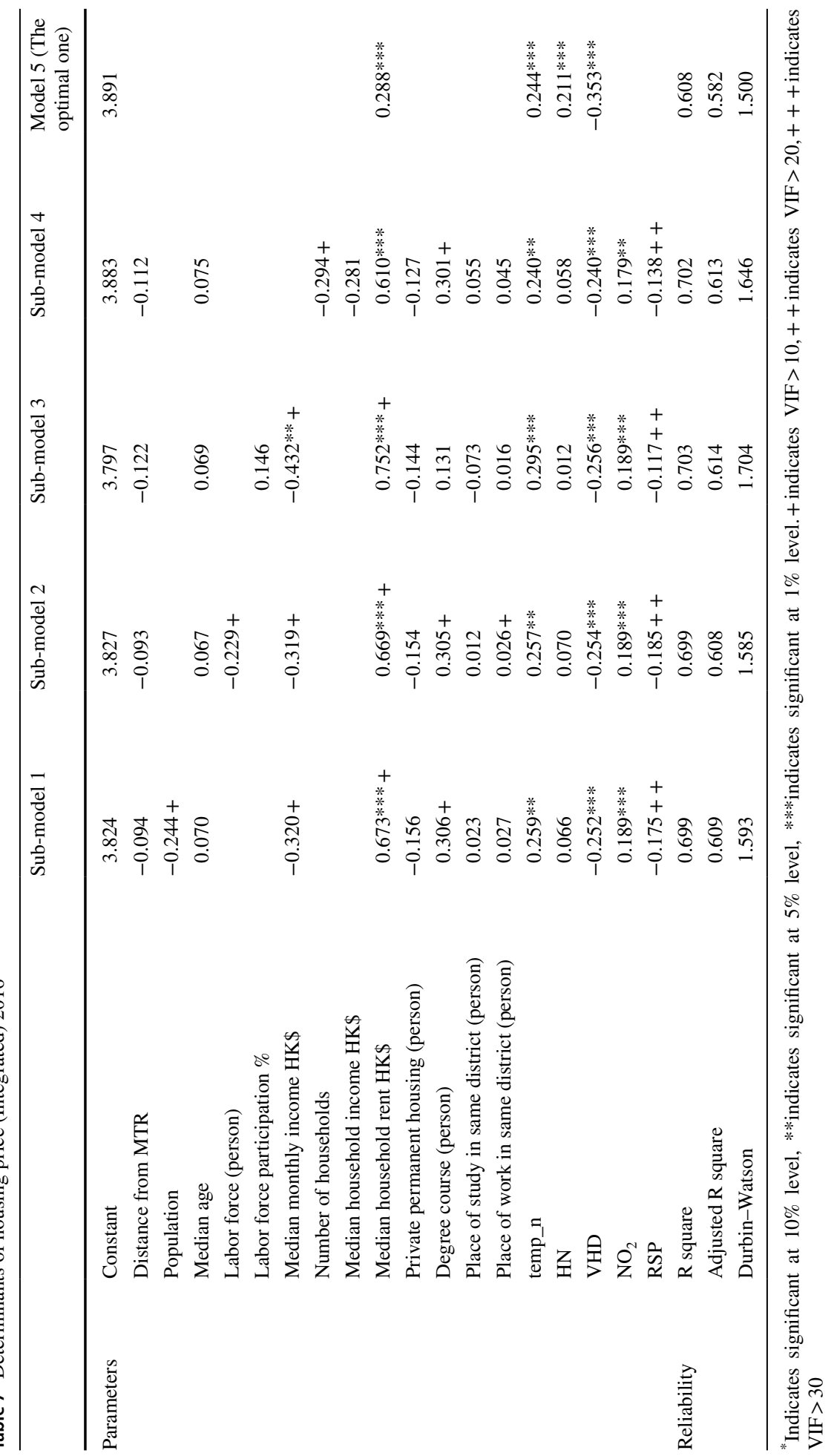




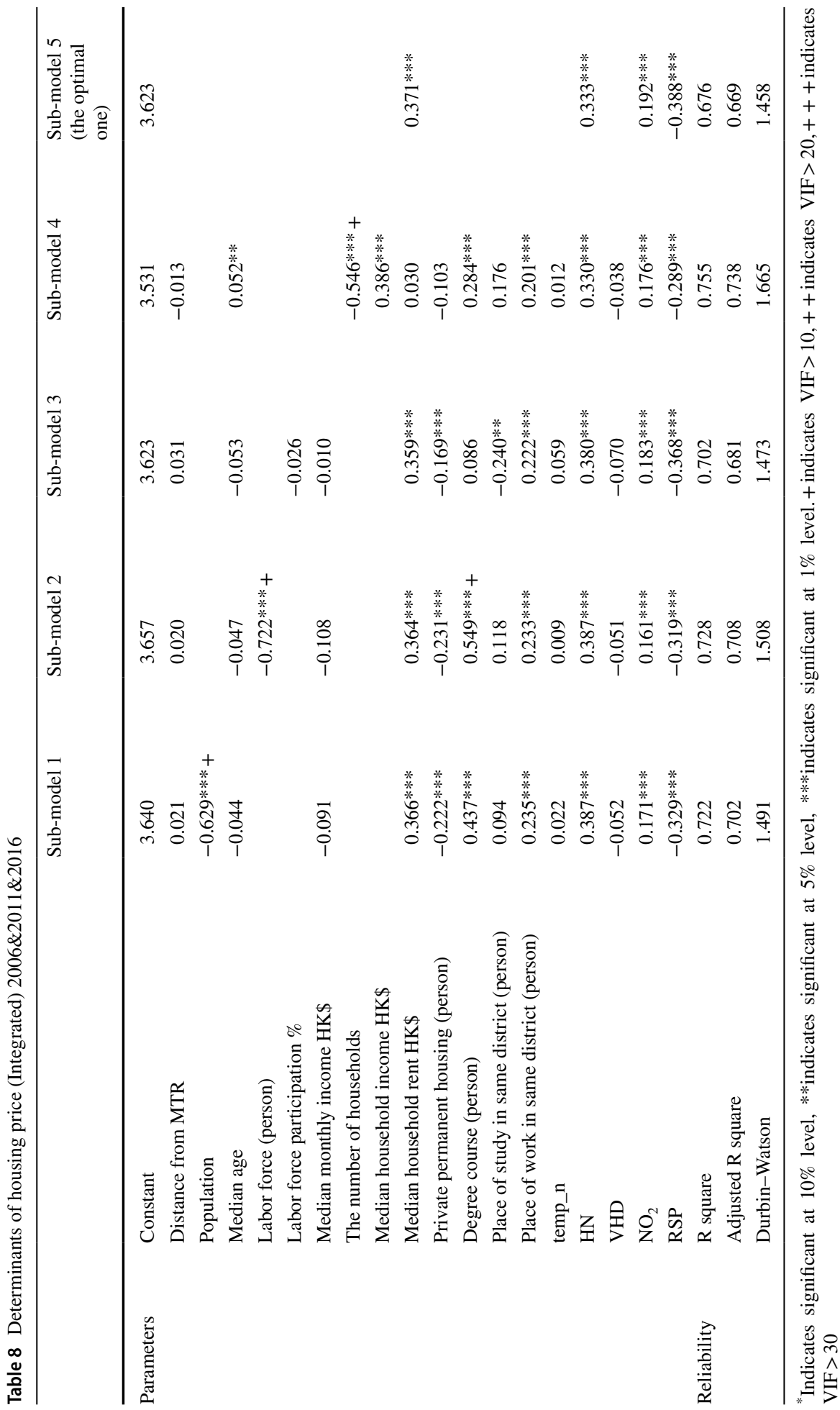



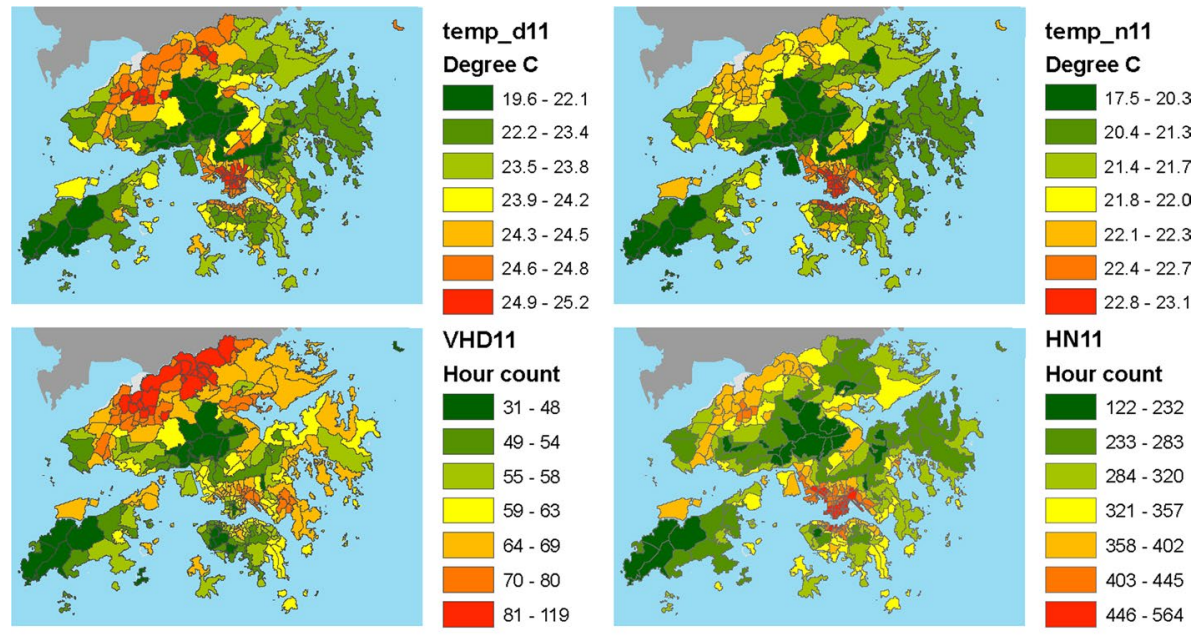

\section{HN11}

Hour count
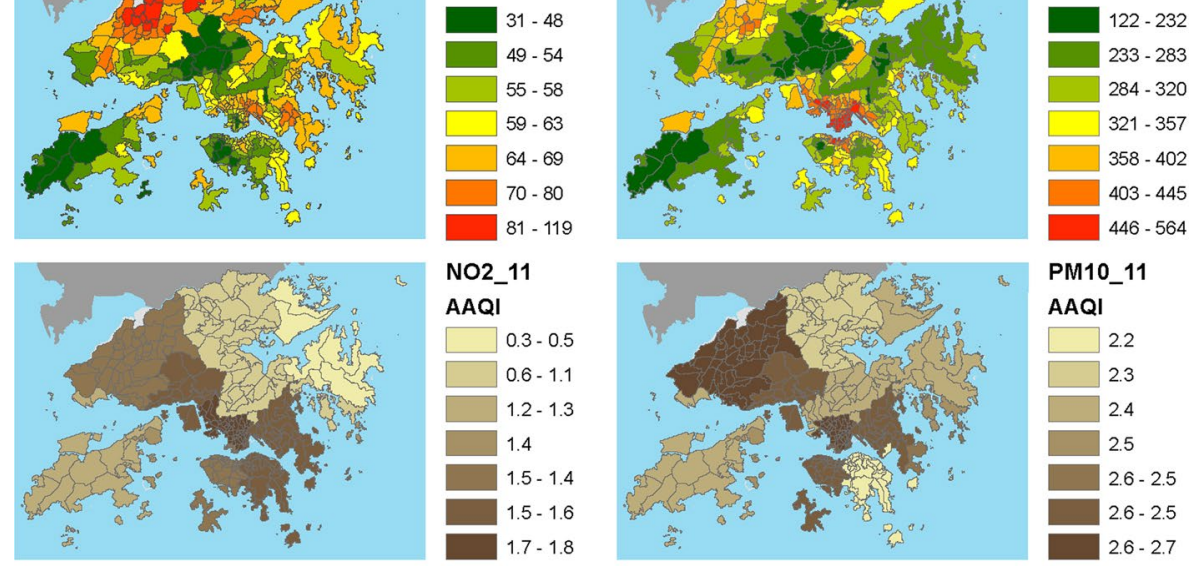

NO2_11

AAQI
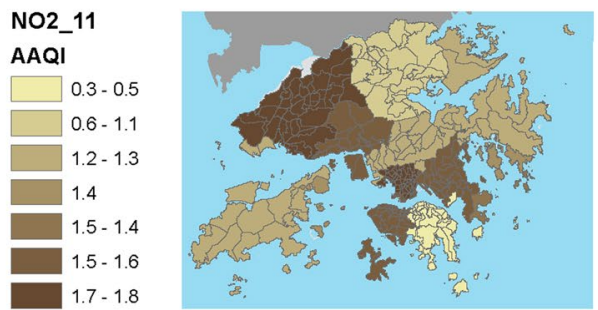

PM10_11

AAQI
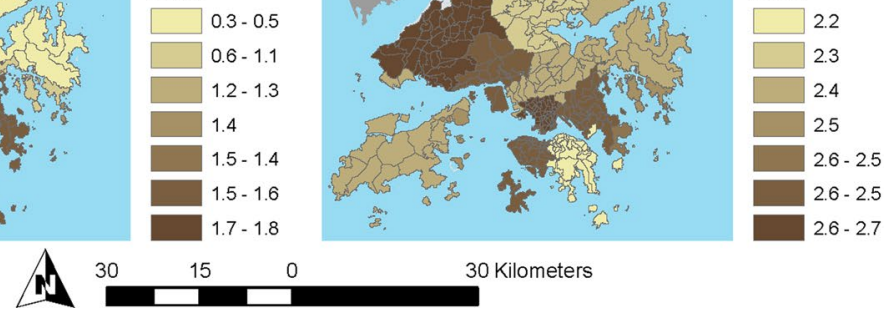

Fig. 1 Geographical distribution maps of the environmental data described in Table 2

However, only medium household rent has a significant and positive effect on housing price in years 2011 and 2016. The implication is that income growth cannot catch up with housing price or rent growth (Li, 2018), in particular for young people over the last decade (Xian \& Forrest, 2019), such that income is insignificant in representing housing demand.

Regarding the housing supply variables, the impact of the number of private permanent housing on housing price is most significant and negative in year 2006 (models 1-3), partly significant and negative in year 2011 (model 2) and insignificant in year 2016. While the society is calling for more housing supply and land reclamation to solve the problems of housing affordability and limited land resources in Hong Kong, our results suggest that it may not be feasible as housing price is increasingly inelastic to supply change in recent years. In fact, some scholars maintained that housing or land supply does not have a significant relationship with housing price (Tse, 1998). Some others argued the impact of supplyside shock on housing price in Hong Kong may be asymmetric: a sudden scarcity of land sharply raises housing price (Peng \& Wheaton, 1994), but the increase of land supply only modestly lowers housing price (Ho \& Ganesan, 1998). This phenomenon is explained by the construction lags between the supply-demand gap (Tse et al., 1999), partly due to the lengthy procedure of approval from the urban planning department (Hui, 2004; Hui \& Ho, 2003). 


\section{Baseline model (Model 1 in Table 3)}

Normal P-P Plot of Regression Standardized Residual
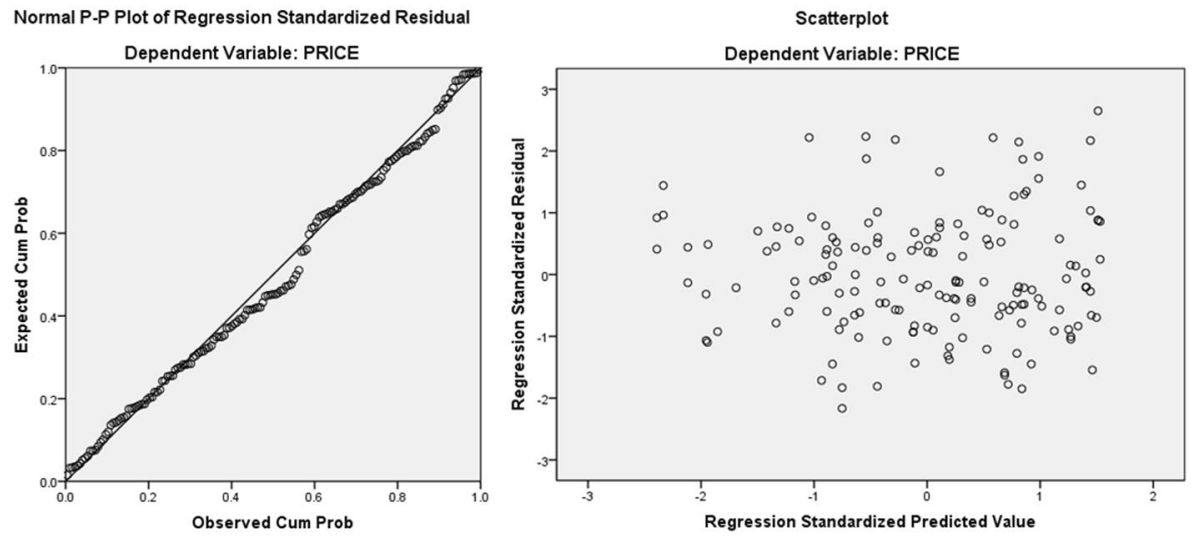

Alternative \& optimal model (Model 2 in Table 3)

Normal P.P Plot of Regression Standardized Residual
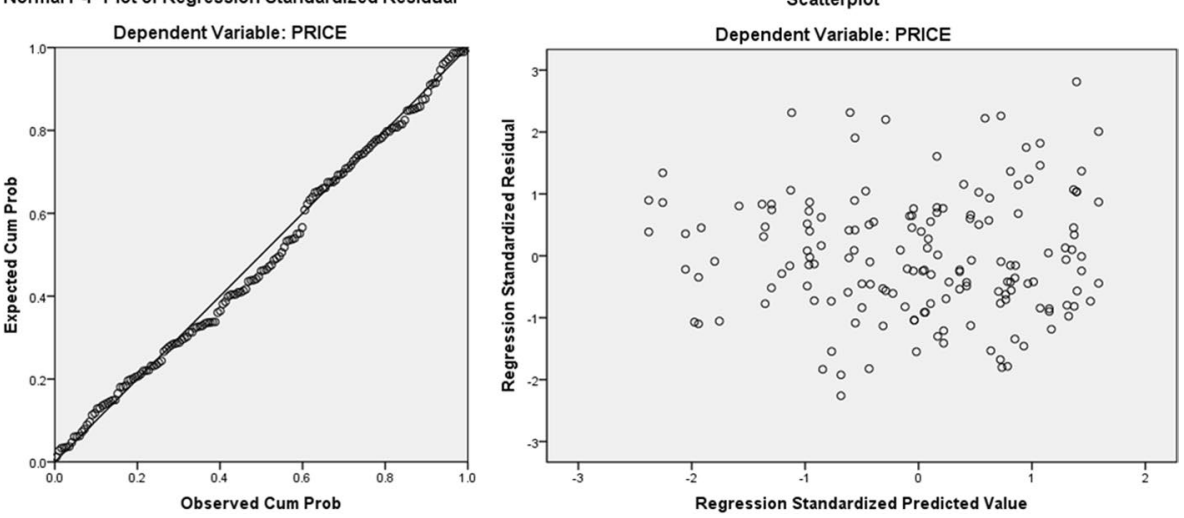

Fig. 2 Estimated residuals of environmental determinants (charts of other models are available upon request)

As for environmental factors, the impact of the number of hot night hours is insignificant in most models except for model 4 of year 2011 and model 5 of year 2016 (the optimal model in Table 6). The impact is positive in both models. The impact of the number of very hot day hours remains significant and negative in all models of years 2006 and 2016, but turns insignificant in models of year 2011. The impact of AAQIs of $\mathrm{NO}_{2}$ is insignificant of years 2006 and 2011, but becomes insignificant and positive of year 2016. The impact of AAQIs of $\mathrm{PM}_{10}$ is significant and negative in all models of year 2006, significant but positive in model 5 of year 2011, and insignificant of year 2016.

Table 8 summarizes the impact of different variables on housing prices over the period 2006 to 2016, with the associated residual distribution for models 1 and 5 displayed in Fig. 7. After combining all variables with a time length of 10 years, it is interesting to note that the impact of distance to MTR becomes insignificant in all models of Table 8. Yet the impact of place of work in the same district by a person is significant and positive. Demographic factors, i.e., total population, medium age, number of labor force and households, are sometimes significant in different models of Table 8 ; however, the signs of their impact vary and may differ 


\section{Baseline model (Model 1 in Table 4)}

Normal P.P Plot of Regression Standardized Residual

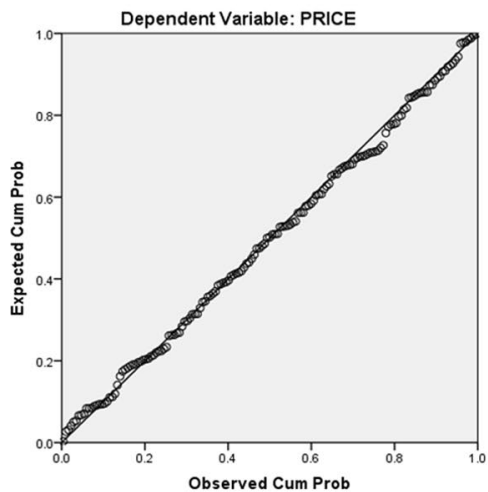

Scatterplot

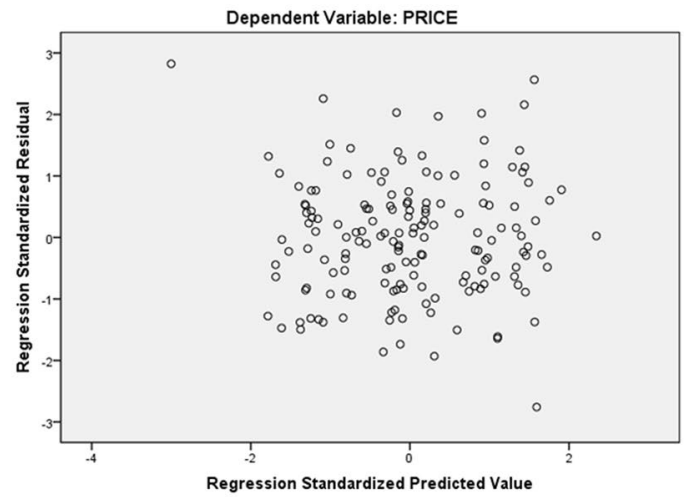

Alternative model (Model 5 in Table 4)

Normal P.P Plot of Regression Standardized Residual
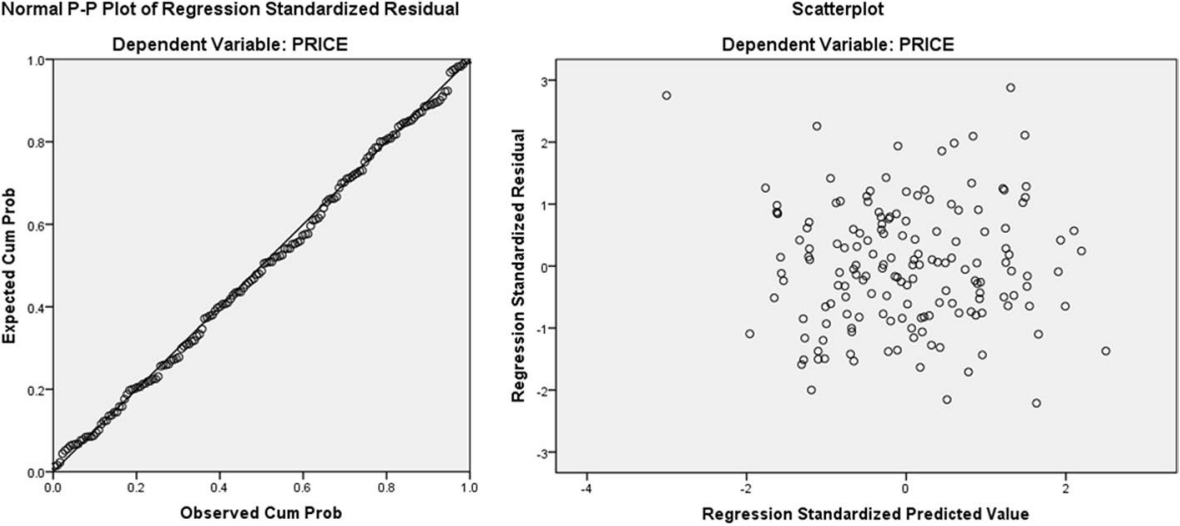

Fig. 3 Estimated residuals of economic and social determinants (charts of other models are available upon request)

from the results of the individual year basis. Housing demand indicator by medium income or rent remains significant and positive in all models of Table 8 , indicating that rigid demand still plays an important role in explaining housing price increase. Supply-side factors such as private housing has a significant and negative effect on housing price, while demand-side factors such as degree course have a significant and positive effect on housing price. It is noteworthy that the majority of environmental variables, including the number of hot night hours, AAQIs of $\mathrm{NO}_{2}$ and $\mathrm{PM}_{10}$, significantly affect housing price in the integrated model over the study period. Specifically, the impacts of hot nights and $\mathrm{NO}_{2}$ are positive, while the impact of $\mathrm{PM}_{10}$ is negative. 


\section{Baseline model (Model 1 in Table 5)}

Normal P-P Plot of Regression Standardized Residual
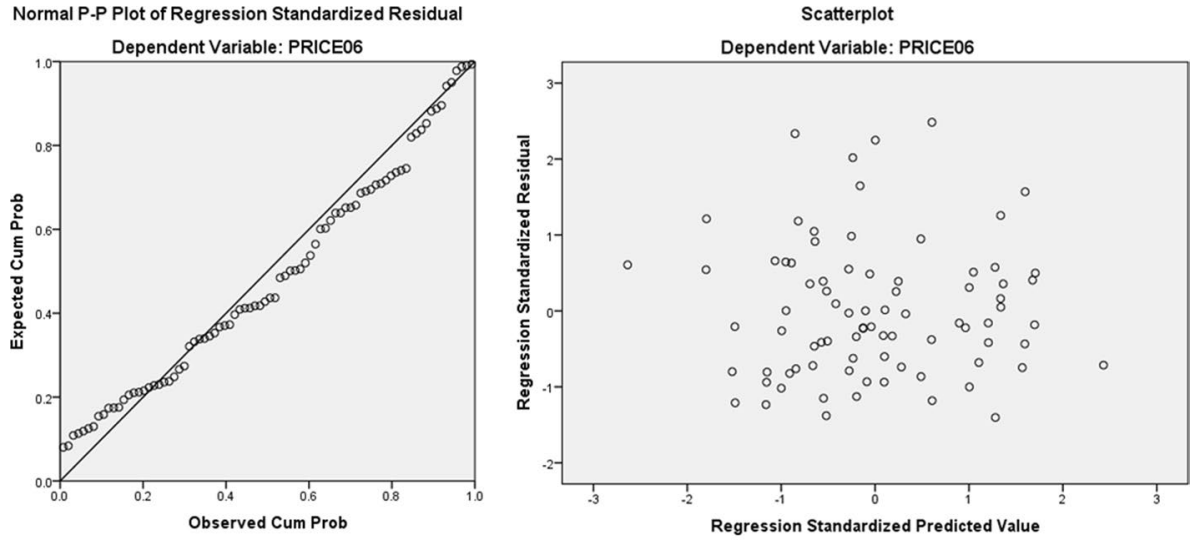

Alternative model (Model 5 in Table 5)

Normal P.P Plot of Regression Standardized Residual
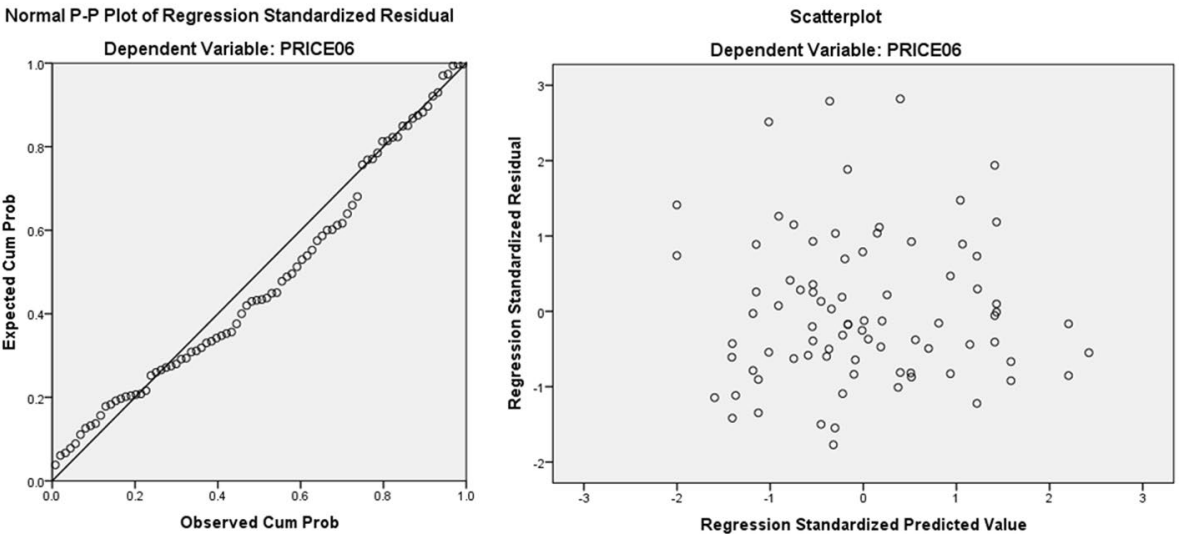

Fig. 4 Estimated residuals of integrated determinants in 2006 (charts of other models are available upon request)

\section{Conclusion}

This paper makes several research contributions: first, it is one of the first studies to compare the impacts of economic, social and environmental factors on housing price in Hong Kong, based on the analysis of a combination of census data and our spatial-temporal environmental database covering all districts with good data quality and representativeness. Second, the empirical results reveal various interesting effects. For instance, the impact of MTR is more significant in individual years rather than over the study period, indicating that announcement or completion of new MTR stations may be more influential to housing prices. The impacts of environmental factors are as expected. Specifically, the impact of PM10 is negative on housing price, indicating that people prefer housing locations with better air quality. Thus, the areas of development nearby the Mainland (i.e., New Territory), which is affected more by the emissions of manufacturing sectors in Shenzhen, may have lower housing prices. 


\section{Baseline model (Model 1 in Table 6)}

Normal P-P Plot of Regression Standardized Residual

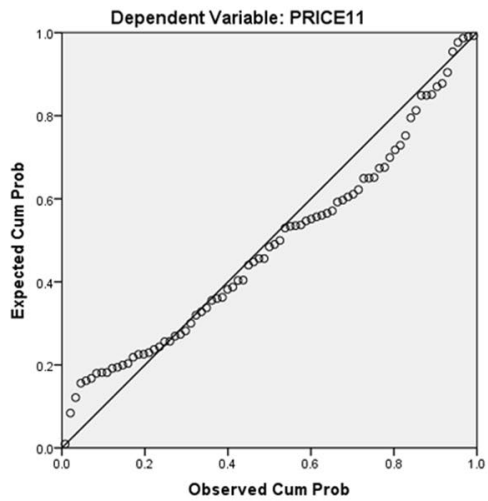

Scatterplot

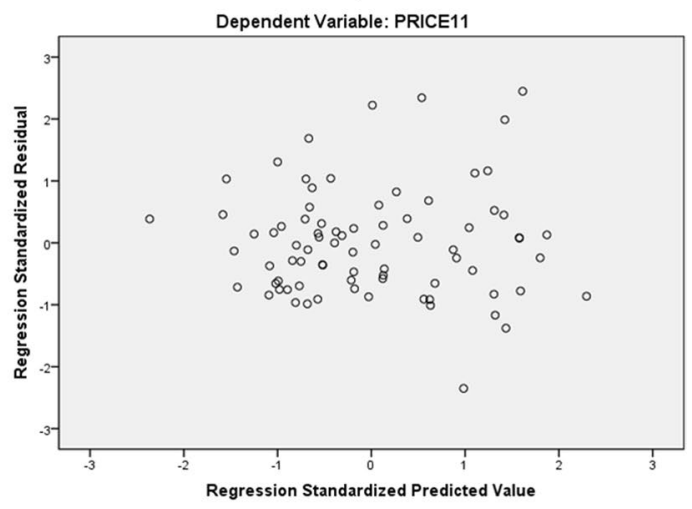

Alternative model (Model 7 in Table 6)

Normal P-P Plot of Regression Standardized Residual
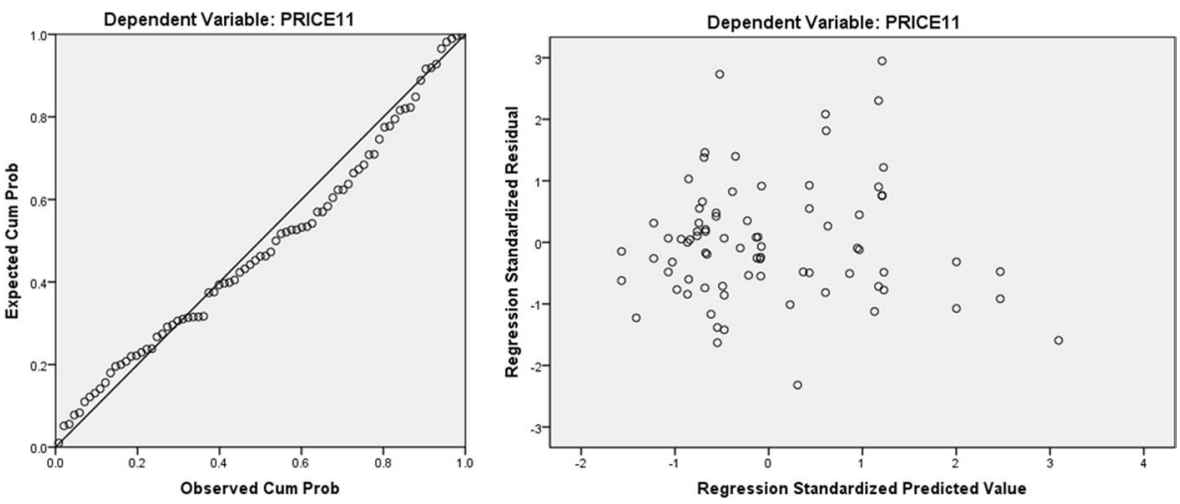

Fig. 5 Estimated residuals of integrated determinants in 2011 (charts of other models are available upon request)

The results thus have important implications: Current policy instruments to prevent housing price escalation are focused on increasing property tax or land supply (economic factors), while little attention is paid to social or environmental factors, which are geographically heterogeneous. Our findings suggest that housing provision in New Territories may be a feasible solution to alleviate the housing crisis as its demographic pattern, transportation connectivity and air quality are significantly different from Hong Kong Island or Kowloon: with lower residential density and more brownfield, New Territories is suitable to accommodate the long-term housing needs of Hong Kong residents for public housing or subsidized housing at more affordable price, due to its relatively underdeveloped transportation system. Still, efforts should be made to improve the air quality through more collaboration in the Greater Bay Area, e.g., between Hong Kong and Shenzhen for more green development schemes. For example, Fang et al. (2019) adopted a multi-scale lag correlation analysis of air quality in the Greater Bay Area cities and found that Foshan, Guangzhou and Dongguan have the worst air quality in the Greater Bay Area. While Hong Kong residents are allowed to buy one housing unit in the Pearl River Delta cities, the 


\section{Baseline model (Model 1 in Table 7)}

Normal P-P Plot of Regression Standardized Residual

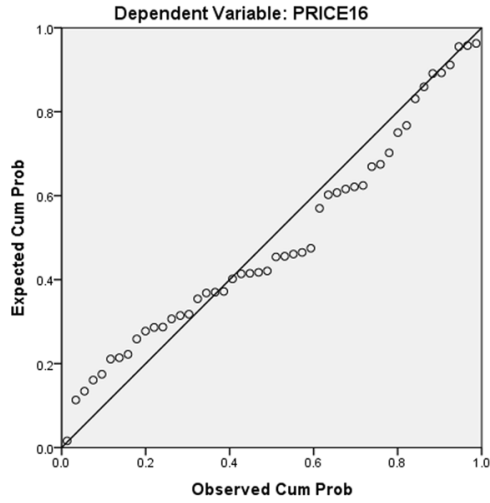

Scatterplot

Dependent Variable: PRICE16

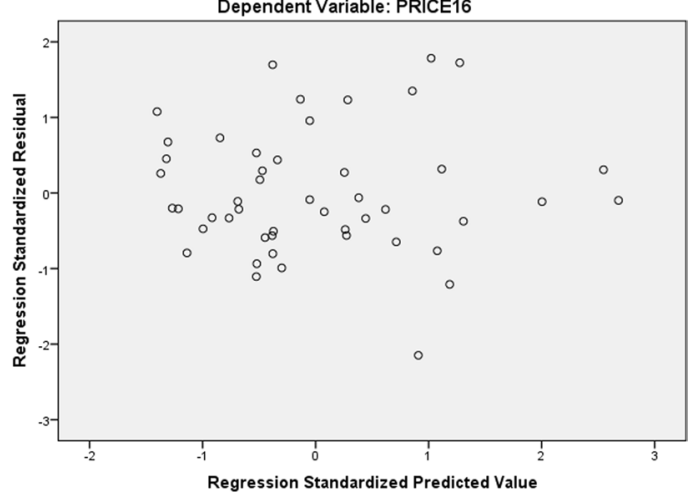

Alternative model (Model 5 in Table 7)

Normal P.P Plot of Regression Standardized Residual

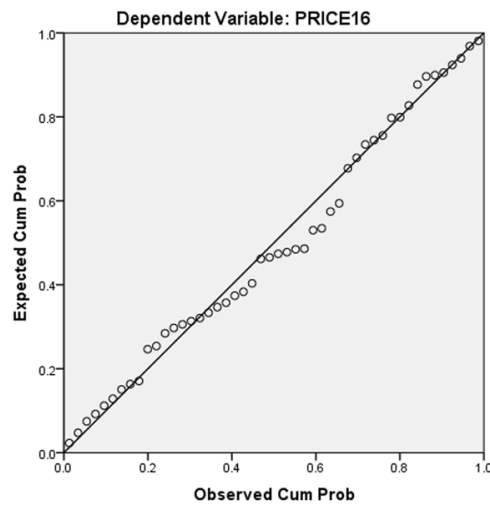

Scatterplot

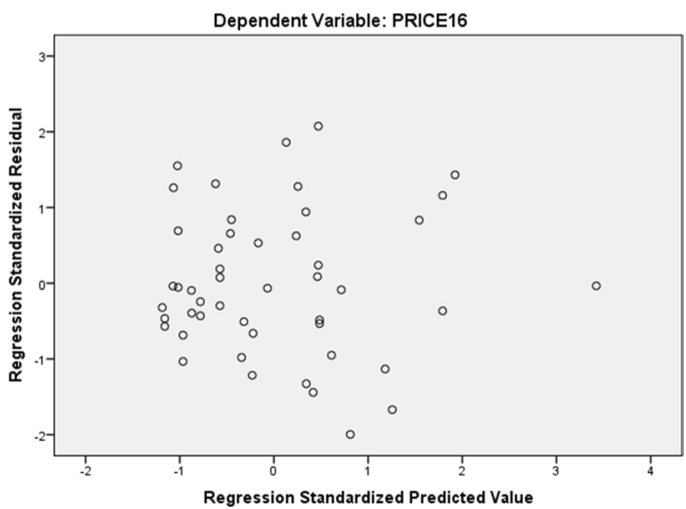

Fig. 6 Estimated residuals of integrated determinants in 2016 (charts of other models are available upon request)

environmental determinants of housing price need to be considered from buyers. Evidence also showed that there is marginal health improvement of Hong Kong people due to the reduction in southern China's pollution (Xiao et al., 2006), when the Pearl River Delta was experiencing rapid economic growth (Zhong et al., 2013). The relationship between air quality and housing choice in Greater Bay Area cities remains to be further explored in future work.

Regarding research limitation, the three waves of census data cover a period when Hong Kong's housing market experienced boom-bust with immigration and tax policy changes. Specifically, Hong Kong's property market reached its first peak in 1997, followed by a $60 \%$ reduction in housing price from 1998 to 2003. Afterward, the housing price went up and continued its uprising trend till present. As for immigration and tax policy changes, the government initiated the Capital Investment Entrant Scheme in 2004 but suspended the 


\section{Baseline model (Model 1 in Table 8)}

Normal P-P Plot of Regression Standardized Residual

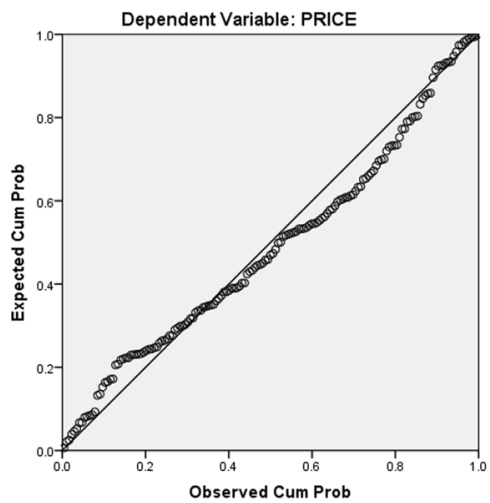

Scatterplot

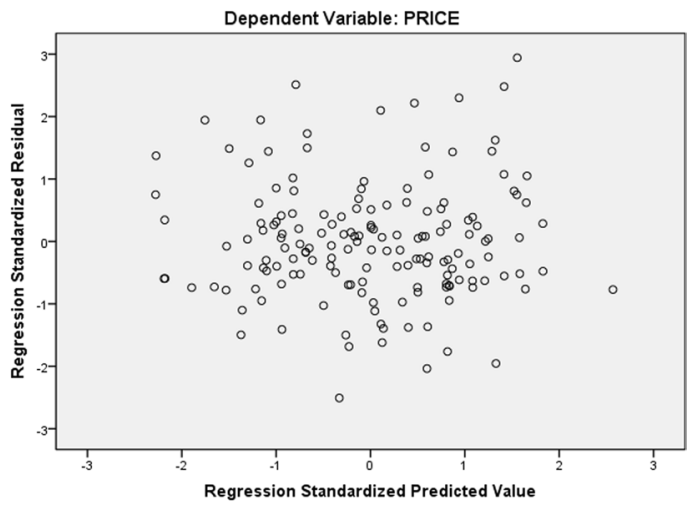

Alternative model (Model 5 in Table 8)

Normal P-P Plot of Regression Standardized Residual
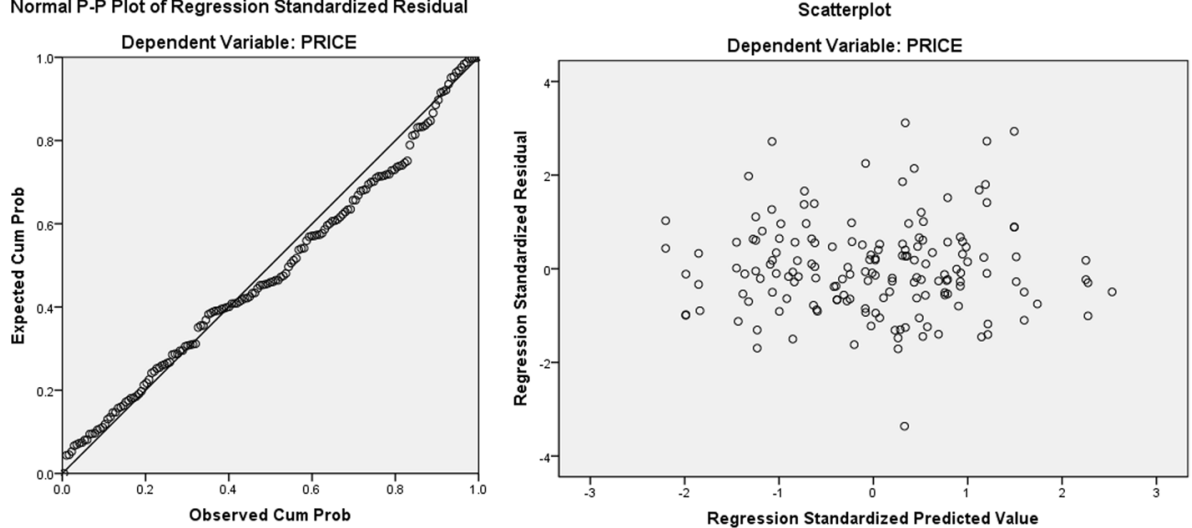

Fig. 7 Estimated residuals of integrated determinants (2006-2016). Charts of other models are available upon request

policy in 2015. The government also charged or increased various taxes on housing buyers in 2010, such as buyer stamp duty, special stamp duty and double ad valorem stamp duty. Data sampling from the years 2001, 2006 and 2011 can therefore sufficiently capture the impacts of these market cycles and policy shocks. Due to the discrete data, we are unable to control the effects of policy shocks on housing price dynamics. Future research is needed to investigate the combined economic, social and environmental impacts under specific policies, i.e., new town development plan in the Northeast New Territories or developing the East Lantau Metropolis, on the housing market dynamics when more continuous data are available.

Acknowledgements This research is supported by the General Research Fund (GRF) No. 14610717 from the Research Grants Council (RGC) of Hong Kong. This study is partially supported by the Vice-Chancellor's One-off Discretionary Fund of The Chinese University of Hong Kong. The authors appreciate reviewers for their insightful comments and constructive suggestions on our research work. The authors also want to thank editors for their patient and meticulous work for our manuscript. 


\section{References}

Bao, H. X., \& Wan, A. T. (2004). On the use of spline smoothing in estimating hedonic housing price models: Empirical evidence using Hong Kong data. Real Estate Economics, 32(3), 487-507.

Bunten, D., \& Kahn, M. E. (2014). The impact of emerging climate risks on urban real estate price dynamics. National Bureau of Economic Research No. w20018

Cai, M., Ren, C., Lau, K. K. L., \& Xu, Y. (2017). Spatial analysis on intra-urban temperature variation under extreme hot weather by incorporating urban planning and environmental parameters: a pilot study from Hong Kong. In: Passive Low Energy Architecture (PLEA) 2017, Edinburgh, Scotland.

Cervero, R., \& Murakami, J. (2009). Rail and property development in Hong Kong: Experiences and extensions. Urban Studies, 46(10), 2019-2043.

Chan, E. H. W., So, H. M., Tang, B. S., \& Wong, W. S. (2008). Private space, shared space and private housing prices in Hong Kong: An exploratory study. Habitat International, 32(3), 336-348.

Chau, K. W., \& Chin, T. L. (2003). A critical review of literature on the hedonic price model. International Journal for Housing Science and Its Applications, 27(2), 145-165.

Chau, K., Ma, V., \& Ho, D. (2001). The pricing of 'luckiness' in the apartment market. Journal of Real Estate Literature, 9(1), 29-40.

Chau, K. W., Wong, S. K., \& Yiu, C. Y. (2004). The value of the provision of a balcony in apartments in Hong Kong. Property Management, 22(3), 250-264.

Chiang, Y. H., Li, V. J., Zhou, L., Wong, F., \& Lam, P. (2016). Evaluating sustainable building-maintenance projects: Balancing economic, social, and environmental impacts in the case of Hong Kong. Journal of Construction Engineering and Management, 142(2), 06015003.

Chiang, Y. H., Zhou, L., Li, J., Lam, P. T. I., \& Wong, K. W. (2014). Achieving sustainable building maintenance through optimizing life-cycle carbon, cost, and labor: Case in Hong Kong. Journal of Construction Engineering and Management, 140(3), 05014001.

Choy, L. H., \& Li, V. J. (2017). The role of higher education in China's inclusive urbanization. Cities, $60,504-510$.

Choy, L. H., Mak, S. W., \& Ho, W. K. (2007). Modeling Hong Kong real estate prices. Journal of Housing and the Built Environment, 22(4), 359-368.

Clark, G., \& Moir, E. (2015). Density: Drivers, dividends and debates. Urban Land Institute.

Environmental Protection Department. (2018). Annual air quality index. http://www.aqhi.gov.hk/en/ annual-aqi/annual-aqi-trend.html. Retrieved on 15 Mar 2018.

Fang, X., Fan, Q., Liao, Z., Xie, J., Xu, X., \& Fan, S. (2019). Spatial-temporal characteristics of the air quality in the Guangdong-Hong Kong-Macau Greater Bay Area of China during 2015-2017. Atmospheric Environment, 210, 14-34.

Forrest, R., \& Xian, S. (2018). Accommodating discontent: Youth, conflict and the housing question in Hong Kong. Housing Studies, 33(1), 1-17.

He, S. Y., Tao, S., Hou, Y., \& Jiang, W. (2018). Mass Transit Railway, transit-oriented development and spatial justice: The competition for prime residential locations in Hong Kong since the 1980s. Town Planning Review, 89(5), 467-493.

Ho, W. K., \& Ganesan, S. (1998). On land supply and the price of residential housing. Netherlands Journal of Housing and the Built Environment, 13(4), 439-452.

Hui, E. C. M. (2004). An empirical study of the effects of land supply and lease conditions on the housing market: A case of Hong Kong. Property Management, 22(2), 127-154.

Hui, E. C. M., \& Ho, V. S. M. (2003). Does the planning system affect housing prices? Theory and with evidence from Hong Kong. Habitat International, 27(3), 339-359.

Hui, E. C., Zhong, J. W., \& Yu, K. H. (2012). The impact of landscape views and storey levels on property prices. Landscape and Urban Planning, 105(1-2), 86-93.

Jim, C. Y., \& Chen, W. Y. (2009). Value of scenic views: Hedonic assessment of private housing in Hong Kong. Landscape and Urban Planning, 91(4), 226-234.

Kenneth, Y. C., \& Michael, G. (2005). Does air quality matter? Evidence from the Housing market. Journal of Political Economy, 113(2), 376-424.

Leung, C. (2004). Macroeconomics and housing: A review of the literature. Journal of Housing Economics, 13(4), 249-267.

Li, J. (2016). Housing Policies in Hong Kong, China and the People's Republic of China. ADBI working paper No. 566 .

Li, J. (2013). What causes China's property boom? Property Management, 31(1), 4-21.

Li, J. (2018). Married to property? Housing price and family formation revisited. International Journal of Home Economics, 11(1), 44-53. 
Li, J., Cheng, W. W., \& Chui, K. H. (2019). Why "Spicy Measures” fail to cool down Hong Kong's housing market? International Journal of Sustainable Real Estate and Construction Economics, 1(4), 298-313.

Li, R. Y. M., Cheng, K. Y., \& Shoaib, M. (2018). Walled buildings, sustainability, and housing prices: An artificial neural network approach. Sustainability, 10(4), 1298.

Li, R., \& Li, H. (2018). Have housing prices gone with the smelly wind? Big data analysis on landfill in Hong Kong. Sustainability, 10(2), 341-359.

Mak, S., Choy, L., \& Ho, W. (2010). Quantile regression estimates of Hong Kong real estate prices. Urban Studies, 47(11), 2461-2472.

Mok, H. M., Chan, P. P., \& Cho, Y. S. (1995). A hedonic price model for private properties in Hong Kong. The Journal of Real Estate Finance and Economics, 10(1), 37-48.

$\mathrm{Ng}$, E. (2009). Policies and technical guidelines for urban planning of high-density cities-air ventilation assessment (AVA) of Hong Kong. Building and Environment, 44(7), 1478-1488.

Peng, R., \& Wheaton, W. C. (1994). Effects of restrictive land supply on housing in Hong Kong: An econometric analysis. Journal of Housing Research, 5(2), 263.

Planning Department. (2018). Urban climatic map and standards for wind environment—feasibility study. https://www.pland.gov.hk/pland_en/p_study/prog_s/ucmapweb/ucmap_project/content/reports/final_ report.pdf. Retrieved on 15 Mar 2018.

Rating and Valuation Department. (2019). https://www.rvd.gov.hk/en/property_market_statistics/index. html. Retrieved on 14 Oct 2019.

Shi, Y., Lau, K.K.-L., \& Ng, E. (2016). Developing street-level PM2.5 and PM10 land use regression models in high-density Hong Kong with urban morphological factors. Environmental Science and Technology, 50(15), 8178-8187.

Shi, Y., Katzschner, L., \& Ng, E. (2018a). Modelling the fine-scale spatiotemporal pattern of urban heat island effect using land use regression approach in a megacity. Science of the Total Environment, 618, 891-904. https://doi.org/10.1016/j.scitotenv.2017.08.252

Shi, Y., Lau, K.K.-L., Ren, C., \& Ng, E. (2018b). Evaluating the local climate zone classification in highdensity heterogeneous urban environment using mobile measurement. Urban Climate, 25, 167-186. https://doi.org/10.1016/j.uclim.2018.07.001

Shi, Y., Ren, C., Cai, M., Lau, K.K.-L., Lee, T.-C., \& Wong, W.-K. (2019). Assessing spatial variability of extreme hot weather conditions in Hong Kong: A land use regression approach. Environmental Research, 171, 403-415.

So, H. M., Tse, R. Y., \& Ganesan, S. (1997). Estimating the influence of transport on house prices: Evidence from Hong Kong. Journal of Property Valuation and Investment, 15(1), 40-47.

Tang, B. S. (2017). Leveraging property values for metro railway development in Hong Kong: Experiences and lessons. In: Routledge Companion to Real Estate Development (pp. 12-27). Routledge.

Tang, B. S., \& Yiu, C. Y. (2010). Space and scale: A study of development intensity and housing price in Hong Kong. Landscape and Urban Planning, 96(3), 172-182.

Tse, R. Y. (1998). Housing price, land supply and revenue from land sales. Urban Studies, 35(8), 1377-1392.

Tse, R. Y. (2002). Estimating neighbourhood effects in house prices: Towards a new hedonic model approach. Urban Studies, 39(7), 1165-1180.

Tse, R. Y., Ho, C. W., \& Ganesan, S. (1999). Matching housing supply and demand: An empirical study of Hong Kong's market. Construction Management and Economics, 17(5), 625-633.

Tse, R. Y., \& Love, P. E. (2000). Measuring residential property values in Hong Kong. Property Management, 18(5), 366-374.

Unit, E. I. (2011). Lievanomics: Urban liveability and economic growth. The Economist.

Wadu, M. J., \& Wan, S. M. (2013). Effect of green labelling on residential property price: A case study in Hong Kong. Journal of Facilities Management, 11(1), 31-51.

Wang, J., Huang, B., Zhang, T., Wong, H., \& Huang, Y. (2018). Impact of housing and community conditions on multidimensional health among middle-and low-income groups in Hong Kong. International Journal of Environmental Research and Public Health, 15(6), 1132.

Wen, H., Xiao, Y., \& Hui, E. C. (2019). Quantile effect of educational facilities on housing price: Do homebuyers of higher-priced housing pay more for educational resources? Cities, 90, 100-112.

Won Kim, C., Phipps, T. T., \& Anselin, L. (2003). Measuring the benefits of air quality improvement: A spatial hedonic approach. Journal of Environmental Economics and Management, 45(1), 24-39.

Wong, G. (2008). Has SARS infected the property market? Evidence from Hong Kong. Journal of Urban Economics, 63(1), 74-95.

Wong, S. K., Chau, K. W., Yau, Y., \& Cheung, A. K. C. (2011). Property price gradients: The vertical dimension. Journal of Housing and the Built Environment, 26(1), 33-45. 
Xian, S., \& Forrest, R. (2019). The post-80s generation: Exploring the attitudes toward family and housing. Journal of Youth Studies, 1, 17.

Xiao, F., Brajer, V., \& Mead, R. W. (2006). Blowing in the wind: The impact of China's Pearl River Delta on Hong Kong's air quality. Science of the Total Environment, 367(1), 96-111.

Yeh, A. G. (2011). High density living in Hong Kong. Paper presented at the Proceedings of the Cities, Health and Well-being conference, London School of Economics and Alfred Herrhausen Society in partnership with the University of Hong Kong, Hong Kong.

Yiu, C. Y., \& Tam, C. S. (2007). Housing price gradient with two workplaces-An empirical study in Hong Kong. Regional Science and Urban Economics, 37(3), 413-429.

Yiu, C. Y., \& Wong, S. K. (2005). The effects of expected transport improvements on housing prices. Urban Studies, 42(1), 113-125.

Zhang, T., \& Huang, B. (2018). Local retail food environment and consumption of fruit and vegetable among adults in Hong Kong. International Journal of Environmental Research and Public Health, 15(10), 2247.

Zhang, X., Shen, L., Tam, V. W., \& Lee, W. W. Y. (2012). Barriers to implement extensive green roof systems: A Hong Kong study. Renewable and Sustainable Energy Reviews, 16(1), 314-319.

Zheng, S., Kahn, M. E., \& Liu, H. (2010). Towards a system of open cities in China: Home prices, FDI flows and air quality in 35 major cities. Regional Science and Urban Economics, 40(1), 1-10.

Zhong, L., Louie, P. K., Zheng, J., Yuan, Z., Yue, D., Ho, J. W., \& Lau, A. K. (2013). Science-policy interplay: Air quality management in the Pearl River Delta region and Hong Kong. Atmospheric Environment, 76, 3-10.

Publisher's Note Springer Nature remains neutral with regard to jurisdictional claims in published maps and institutional affiliations.

\section{Authors and Affiliations}

\section{Jing $\mathrm{Li}^{1} \cdot$ Weixuan Fang ${ }^{2} \cdot$ Yuan $\mathrm{Shi}^{3}$ (D) Chao Ren ${ }^{4}$}

Jing Li

victorli@cuhk.edu.hk

Weixuan Fang

rn19865@bristol.ac.uk

Chao Ren

renchao@hku.hk

1 Department of Geography and Resource Management and Institute of Future Cities, The Chinese University of Hong Kong, Shatin, New Territories, Hong Kong, China

2 Centre for Urban and Public Policy Research, University of Bristol, Beacon House, Queens Road, Bristol, UK

3 Institute of Future Cities, The Chinese University of Hong Kong, Room 905, YIA Building, Shatin, New Territories, Hong Kong, China

4 Faculty of Architecture, University of Hong Kong, Shatin, New Territories, Hong Kong, China 